\title{
Amicrobial Pustulosis of the Folds
}

VENESSA PENA-ROBICHAUX, MD; ASMA HASAN, BS; CHAUNCEY McHARGUE, MD, Department of Dermatology, Henry Ford Health System, 3031 West Grand Blvd., Suite 800, Detroit, Michigan 48202, USA. Address correspondence to Dr. Pena-Robichaux; E-mail: vpena1@hfhs.org

J Rheumatology 2013;40:1228-9; doi:10.3899/jrheum.130165

Amicrobial pustulosis of the folds (APF) is a rare, chronic, relapsing cutaneous disease seen almost exclusively in young women with a history of autoimmune disease, most commonly systemic lupus erythematosus (SLE), or who simply have circulating autoantibodies ${ }^{1,2,3}$. APF is characterized by recurrent crops of pustules primarily in the skin folds and periorificial regions that eventually coalesce into plaques. To our knowledge there are fewer than 30 cases in the literature to date.

A 22-year-old African American woman with a history of SLE and taking hydroxychloroquine presented with a 1-year history of a recurrent generalized pruritic pustular eruption. She had multiple hospitalizations for this cutaneous eruption, which was originally thought to be superinfected atopic dermatitis, but had no resolution with topical steroids or oral antibiotics. Examination revealed multiple pustules

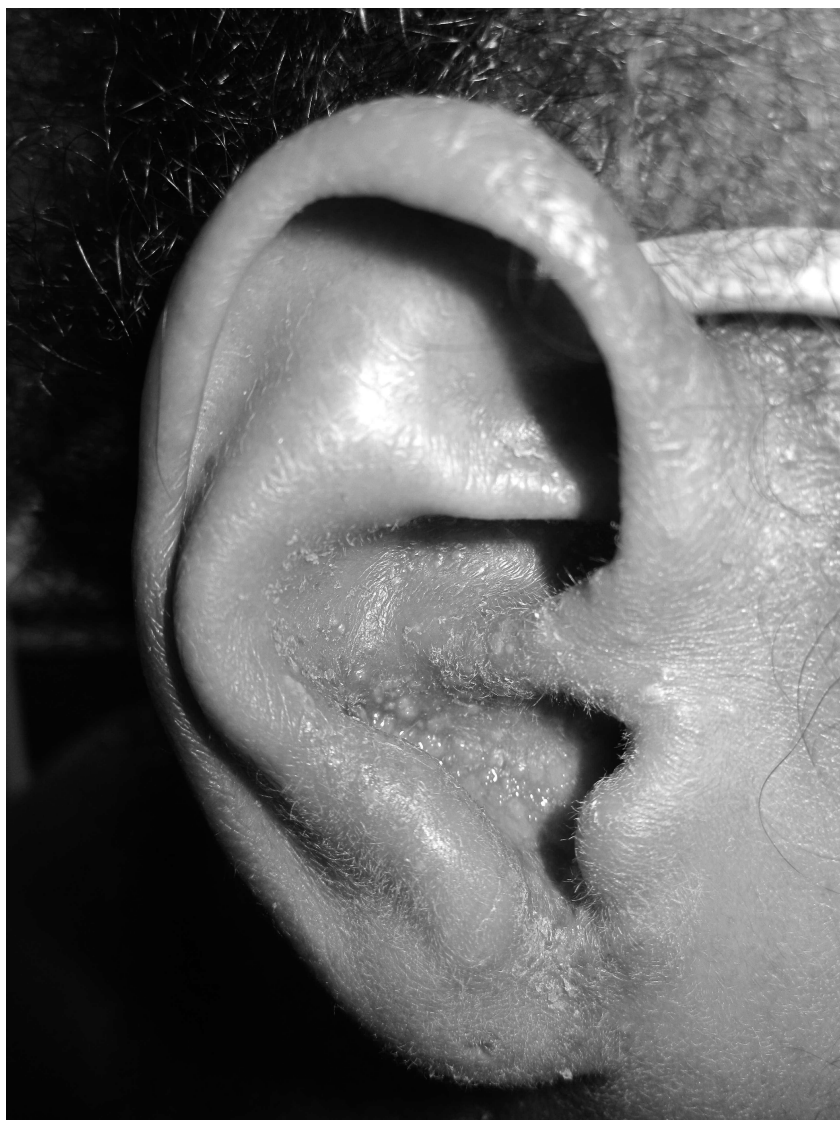

Figure 1. Small pustules with underlying erythema are seen in the right conchal bowl. with underlying erythema throughout the scalp, bilateral conchal bowls (Figure 1), forehead, eyelids, nasal ala, bilateral inframammary folds, and flanks. On the bilateral thighs and groin there were erythematous papules and pustules coalescing into plaques (Figure 2). Skin biopsy and clinical presentation was consistent with APF.

The cause of APF is unknown, but is thought to be related to immune-complex activation of complement leading to neutrophil chemotaxis ${ }^{1,4}$. Recently, APF has been classified within the spectrum of neutrophilic dermatoses, which are now considered autoinflammatory diseases ${ }^{4,5}$. Flares of autoimmune disease have not been shown to correlate with the severity of $\mathrm{APF}^{1,2}$. There is no standard therapy established for APF, because multiple immune-modulating therapies have failed to show consistent longterm success ${ }^{1,2}$. Despite treatment with potent topical steroids and azathioprine, our patient has had no significant improvement to date.

\section{REFERENCES}

1. Boms S, Gambichler T. Review of literature on amicrobial pustulosis of the folds associated with autoimmune disorders. Am J Clin Dermatol 2006;7:369-74.

2. Marzano AV, Ramoni S, Caputo R. Amicrobial pustulosis of the folds: report of 6 cases and a literature review. Dermatology 2008;216:315-21.

3. Marzano AV, Capsoni F, Berti E, Gasparini G, Bottelli S, Caputo R. Amicrobial pustular dermatosis of cutaneous folds associated with

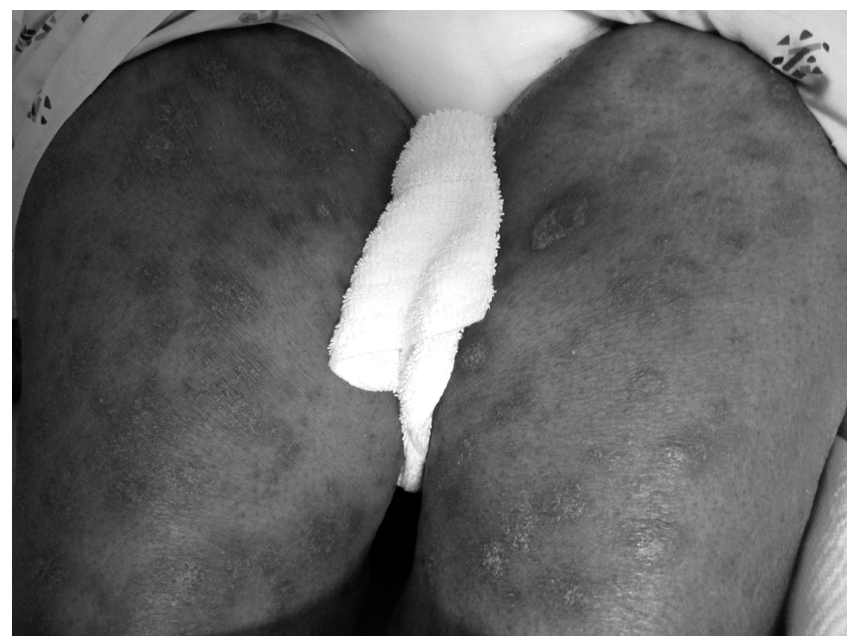

Figure 2. Erythematous papules and pustules have coalesced into plaques on the bilateral thighs. 
autoimmune disorders: a new entity? Dermatology 1996;193:88-93.

4. Marzano AV, Cugno M, Trevisan V, Lazzari R, Fanoni D, Berti E, et al. Inflammatory cells, cytokines and matrix metalloproteinases in amicrobial pustulosis of the folds and other neutrophilic dermatoses. Int J Immunopathol Pharmacol 2011;24:451-60.
5. Marzano AV, Ishak RS, Saibeni S, Crosti C, Meroni PL, Cugno M. Autoinflammatory skin disorders in inflammatory bowel diseases, pyoderma gangrenosum and Sweet's syndrome: A comprehensive review and disease classification criteria. Clin Rev Allergy Immunol 2013 Jan 20. [E-pub ahead of print] 